Article

\title{
Investigation of Barkhausen Noise Emission in Steel Wires Subjected to Different Surface Treatments
}

\author{
Lukáš Krkoška ${ }^{1}$, Martin Moravčík ${ }^{1}$, Katarína Zgútová ${ }^{1}$, Miroslav Neslušan ${ }^{2, *}$, \\ Milan Uhričík $^{2}{ }^{\circledR}$, František Bahleda ${ }^{1}$ and Martin Pitoňák ${ }^{1}$ \\ 1 Faculty of Civil Engineering, University of Žilina, Univerzitná 1, 01026 Žilina, Slovakia; \\ lukas.krkoska@fstav.uniza.sk (L.K.); martin.moravcik@fstav.uniza.sk (M.M.); \\ katarina.zgutova@fstav.uniza.sk (K.Z.); frantisek.bahleda@fstav.uniza.sk (F.B.); \\ martin.pitonak@fstav.uniza.sk (M.P.) \\ 2 Faculty of Mechanical Engineering, University of Žilina, Univerzitná 1, 01026 Žilina, Slovakia; \\ milan.uhricik@fstroj.uniza.sk \\ * Correspondence: miroslav.neslusan@fstroj.uniza.sk; Tel.: +421-908-811-973
}

Received: 8 September 2020; Accepted: 22 September 2020; Published: 23 September 2020

\begin{abstract}
Steel rope wires represent the main bearing components of bridges whose long-term operation depends on loading conditions, corrosion attack, and/or pre-stressing. Corrosion attack especially can remarkably reduce the effective cross-sectional area, which in turn over-stresses the wires and redistributes stress to the neighboring wires. The premature collapse of many bridges is very often caused by wire rupture as a result of their poor corrosion protection. For these reasons, various processes—-such as galvanizing, phosphating, etc.- -have been applied to steel wires to increase their resistance against corrosion. However, these processes can alter the microstructure, especially in the near-surface regions. The Barkhausen noise technique has been already reported as a suitable technique for investigating corrosion extent and true pre-stress in the steel rope wires. This study reports that non-homogeneity of the surface state of wires undergoing different surface treatment makes it more difficult to assess the true stress state and increase the uncertainty of Barkhausen noise measurement. Barkhausen noise signals are correlated with metallographic and SEM observations as well as microhardness measurements. The non-homogeneity of the surface state of wires is also investigated by the use of chemical mapping and linear chemical analyses.
\end{abstract}

Keywords: Barkhausen noise; steel wires; galvanizing; phosphating; stress state

\section{Introduction}

Magnetic Barkhausen noise (MBN) is a function of the stress state [1], its variation [2] as well as microstructure of ferromagnetic bodies [3]. MBN refers to the irreversible and discontinuous jumps of domain walls (DWs) [4] whose sudden displacement, initiated by altering the magnetic field, produces electromagnetic (as well as acoustic) pulses [5]. These pulses can be detected on the free surface using a suitable pick-up coil. Their magnitude depends on the DWs' alignment, the free path of DW motion, the strength of the magnetic field to unpin DWs, and the capability of the sensing system to distinguish among the individual pulses. It is well known that DWs align with the direction of tensile stress and contribute to the increasing magnitude of MBN pulses, thus producing higher MBN emission, whereas compressive stress aligns DWs in the direction perpendicular to the direction of the stresses, which in turn decreases MBN [6]. This behavior explains the sensitivity of MBN against the different magnitudes and regimes of stresses and has been already reported [7]. The MBN technique has been already introduced as a method capable of assessing the real stress state in steel rope wires [8] and the 
extent of corrosion in the wires as a result of long term operation [9]. Finally, MBN can be adapted for monitoring wires for over-stressing [10].

Over-stressing can occur as a result of aggressive corrosion attack, the corresponding reduction of the effective cross-section area and the corresponding increase of true stress. Over-stressing as a result of heavy corrosion can attain the ultimate strength of components and results in their rupture. Furthermore, the rupture of certain components in the structure can redistribute stress to the neighboring regions [11] and accelerate its collapse [12]. Convectional steel wires are usually produced by drawing in dies, quenching, and subsequent high-temperature tempering to obtain a combination of high strength and acceptable toughness. To improve the corrosion resistance of steel wires in operation, these wires can be subjected to further surface treatment such as phosphating, galvanizing, or a combination of galvanizing and plastic deformation in the die (referred as compacting).

It is well known that alterations in the near-surface layer can contribute to the MBN. For example, thermal softening of hardened components increases MBN [13], whereas surface mechanical hardening [14] or/and thermal hardening decreases MBN [15]. Stupakov [16] reported about the remarkable contribution of the surface de-carburized layer to the MBN whereas Santa-aho [17] demonstrated a reduction of MBN as a result of the thin layer containing only non-ferromagnetic nitrides on the surface after plasma nitridation. Čillikova et al. [18] also reported about MBN originating from hardened components subjected to a coating process and compared samples undergoing different coating regimes and the corresponding thicknesses of the near-surface non-ferromagnetic layer and underlying ferromagnetic matrix. Additionally, Seemuang and Slatter [19] adapted the MBN technique for evaluating the coating thickness of high-speed steel.

This paper deals with the non-homogeneity of MBN emission originating from steel rope wires subjected to different processing (phosphating, galvanizing, compacting) and compares the obtained data with conventional wires (quenched and high temperature tempered only). This study also investigates how the non-homogeneity in the surface state affects relationships among the tensile stress and MBN parameters extracted from the raw MBN signals.

\section{Experimental Details}

The experiments were carried out using new wires with a nominal diameter of $5.4 \mathrm{~mm}$ (ultimate strength of $1867 \mathrm{MPa}$ and hardness of $485 \pm 12 \mathrm{HV} 0.2$ in the wire center and $500 \pm 9 \mathrm{HV} 0.2$ near to the wire surface - valid for the conventional wires only after quenching and high-temperature tempering). The nominal chemical composition of the investigated wires is shown in Table 1 . The bulk microstructure of the wires is composed of a ferromagnetic sorbitic-pearlite structure, as Figure 1 illustrates.

Table 1. Chemical composition of the investigated wires (wt \%).

\begin{tabular}{ccccccccccc}
\hline Fe & $\mathbf{C}$ & $\mathbf{M n}$ & $\mathbf{S i}$ & $\mathbf{P}$ & $\mathbf{S}$ & $\mathbf{C r}$ & $\mathbf{N i}$ & $\mathbf{C u}$ & $\mathbf{V}$ & $\mathbf{M o}$ \\
\hline Balance & 1.060 & 0.361 & 0.408 & 0.029 & 0.068 & 0.128 & 0.048 & 0.184 & 0.005 & $<0.001$ \\
\hline
\end{tabular}

Experiments were carried out on the four different wires as follows (the details about the exact conditions were kept secret by the manufacturer):

- the conventional one (quenched and high temperature tempered),

- $\quad$ phosphated (Zn phosphated after quenching + high-temperature tempering),

- galvanized (galvanized after quenching + high-temperature tempering),

- compacted (galvanized and subsequently plastically deformed by drawing in a die).

Microhardness (HV0.2) was measured using an Innova Test $400^{\mathrm{TM}}$ (Innovatest, Maastricht, The Netherlands) tester by applying a $200 \mathrm{~g}$ force for $10 \mathrm{~s}$ on the longitudinal cuts. Microhardness values (as well as the standard deviations) were obtained from five repeated measurements. The microhardness was measured in different positions with respect to the cross-section perimeter of wires. However, 
the most important information for the microhardness and corresponding dislocation density was obtained from the near-surface measurements due to the limited sensing depth of MBN.

To reveal the microstructure of the wires, all wires were cut using a Struers Secotom 50 (Struers Inc., Cleveland, $\mathrm{OH}, \mathrm{USA}$ ) in the longitudinal and perpendicular directions. The cut specimens were hot molded, ground, polished, and etched with 3\% Nital for $5 \mathrm{~s}$. The hot-molded specimens were used for microhardness measurements as well. The macro and microstructure of the samples were observed using the light microscopes (LM) Olympus SZx16 and Zeiss AxioCam MRc5 (Boston Microscopes, MA, USA). Scanning electron microscopy (SEM) was carried out using a Tescan Vega LMU (Tescan, Brno, Czech Republic) microscope equipped with a Brucker energy dispersive X-ray analyzer.

MBN was analyzed using a RollScan 350 (Stresstech, Jyväskylä, Finland) and MicroScan 600 software (mag. voltage $5 \mathrm{~V}$, mag. frequency $125 \mathrm{~Hz}$, sensor type S1-18-12-01, frequency range of MBN pulses $30-180 \mathrm{kHz}$ ). MBN values were obtained by averaging six MBN bursts (three magnetizing cycles). MBN refers to the rms (effective) value of the signal. The wires were magnetized along their axis when the $200 \mathrm{~mm}$ long wires were loaded an Instron 5985 (Instron, Norwood, MA, USA) device. Tensile stresses gradually increased in $100 \mathrm{MPa}$ increments up to $1200 \mathrm{MPa}$. A brief sketch of the sensor positioning and magnetization can be found in a previous study [9]. The sensor position during the measurement was fixed using a self-made stand. The force in the interface between the sensor and wire was kept constant using a spring (further details can be found in [10]).

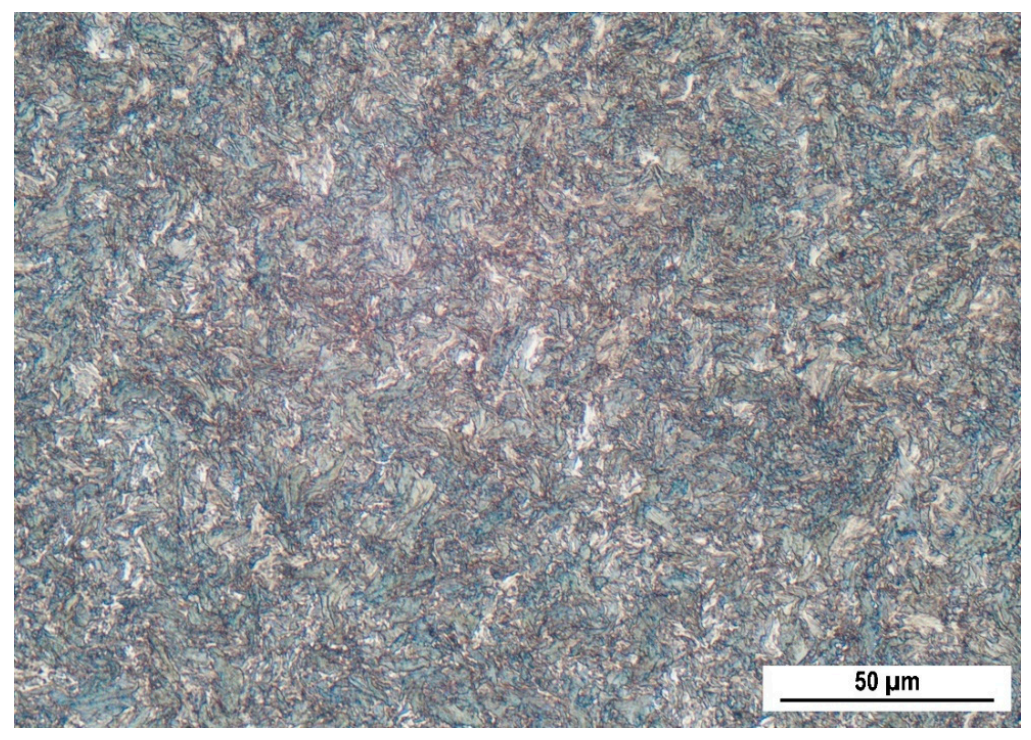

Figure 1. Sorbitic-pearlite microstructure-cross-sectional view.

\section{Results of Experiments and Their Discussion}

\subsection{Microhardness, LM, and SEM Observation}

Figure 2 shows that the microhardness in the center of the conventional wires is less than that in the near-surface regions. This behavior is due to the more intensive plastic deformation in the near-surface region during wires sizing in dies (friction). The phosphated wire exhibits slightly higher microhardness in the deeper wire regions and remarkable lower microhardness in the thin near-surface layer. The galvanized wire exhibits higher microhardness in the deeper regions (compared with the conventional and phosphated wires). However, thermal softening penetrates much deeper. It is considered that this thermal softening is due to thermal effect during wires' thermo-chemical processing. Furthermore, the microhardness profiles for the galvanized and compacted wires are asymmetrical with respect to the wire diameter. Finally, the compacted wire exhibits the highest microhardness due to strain hardening during drawing as the last step of the wire processing. 


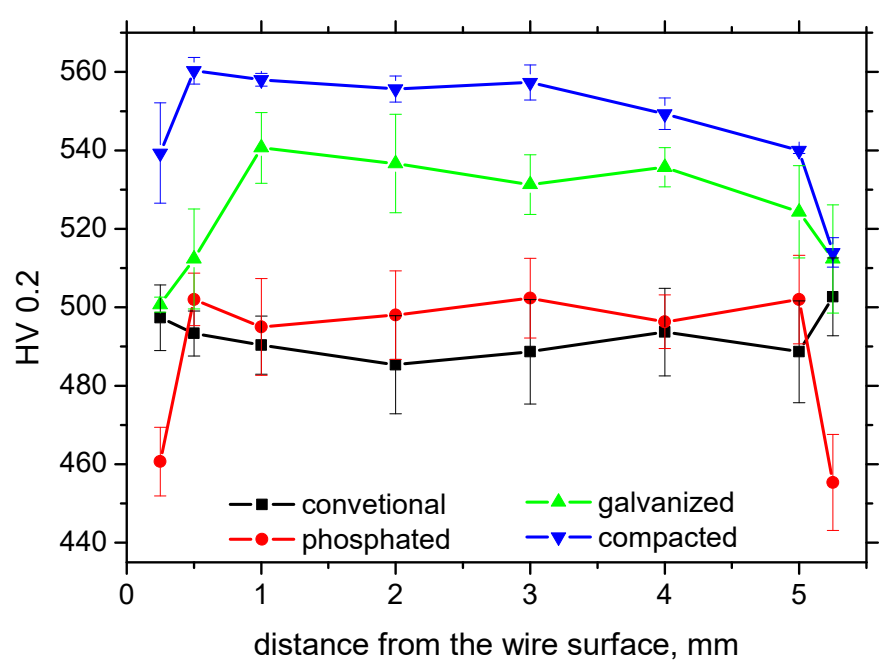

Figure 2. Evolution of microhardness HV0.2 across the wire diameter.

The asymmetry of the microhardness in the case of galvanized and compacted wires originated from the surface state non-homogeneity and the corresponding variable thickness of the galvanized layer, as seen in Figure 3c,d (see also Figures 4 and 5). Missing detail information about the wires processing makes it difficult to explain why the galvanized layer is distributed non-homogenously around the wires surface, why the galvanized layer thickness varies from zero (position 1) up to $42 \mu \mathrm{m}$ (position 4), see also Figure 4. Figures 4 and 5 also demonstrate that the positions in which zero galvanized layer is found exhibit notches, as contrasted to the positions with a deposited galvanized layer (their surface is more or less smooth). These notches can be found on the surface of phosphated wire as well (see Figure 6) and on the SEM images, such as that illustrated in Figure 7. Zn layer in the notched positions occurs in the form of localized regions whereas the thick and continuous $\mathrm{Zn}$ layer of variable thickness can be found in the positions 4 (see Figure 7). The depth of notches strongly varies through the wires periphery. It is considered that the remarkable differences in the wires' appearance with respect of their circumference is driven by non-homogenous conditions during the wires' thermo-chemical processing. No remarkable differences can be found on metallographic images for the conventional wire and the surface state in all positions is comparable with that depicted in Figure 6b. Furthermore, Figures 4 and 5 also illustrate that the galvanizing process initiates surface decarburizing, which appears white on LM images. This zone corresponds to the thermally softened region indicated by microhardness measurement. However, plastic deformation of compacted wires makes the thickness of the galvanized layer more homogenous (as Figure 5 depicts) and produces wire with a hexagonal profile. Due to the remarkable non-homogeneity in thickness of the galvanized layer on the wires' surface, as well as the corresponding depth in which decarburizing takes place, MBN measurements (as well as the conventional destructive analysis) were carried in four different positions, as Figure 3 illustrates. In the case of compacted wire (containing six flat regions), only 1 , the galvanizing free surface (position 1), was compared with those containing a galvanized layer (positions 2, 3, and 4).

Chemical mapping (shown in Figures 8-11) shows a Zn rich coating layer of variable thickness, indicated by green, and an underlying steel matrix. The positions in which zero coating layer was detected (positions 1) exhibit strongly reduced Zn fraction (see Figures 8 and 9). Zn layer occurs in the form of localized regions as contrasted against the positions in which thick and continuous $\mathrm{Zn}$ layer can be found. Moreover, linear chemical analysis depicted in Figures 10 and 11 illustrates much lower $\mathrm{Zn}$ content in the near surface regions for the positions in which zero coating layer was detected (positions 1) as compared with positions 4 . The increase of $\mathrm{Zn}$ content in positions 1 is gentle and occurs in the narrow region only. 


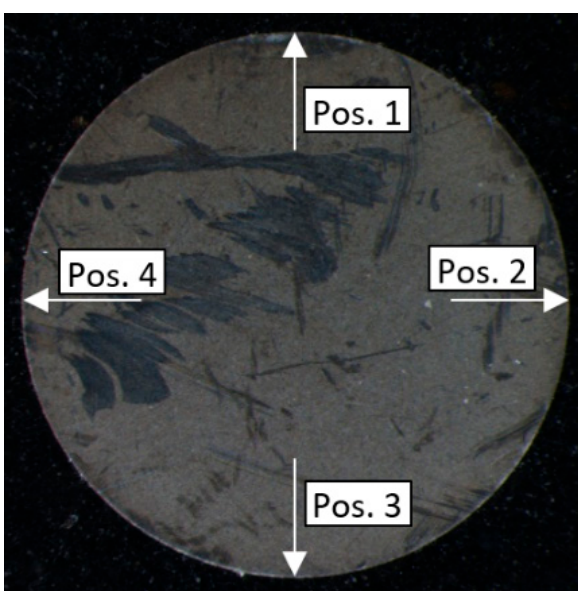

(a)

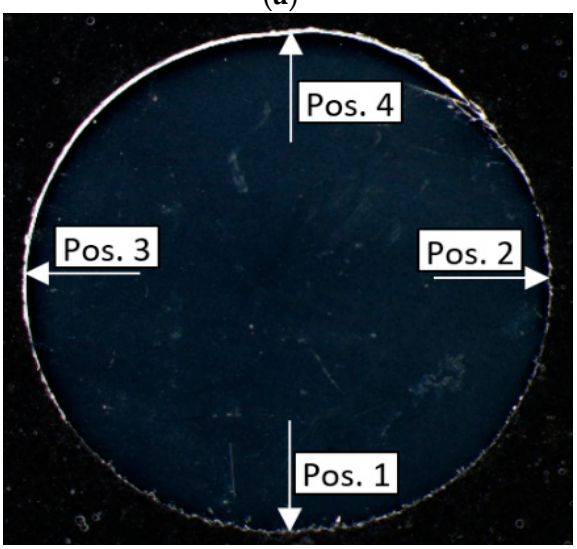

(c)

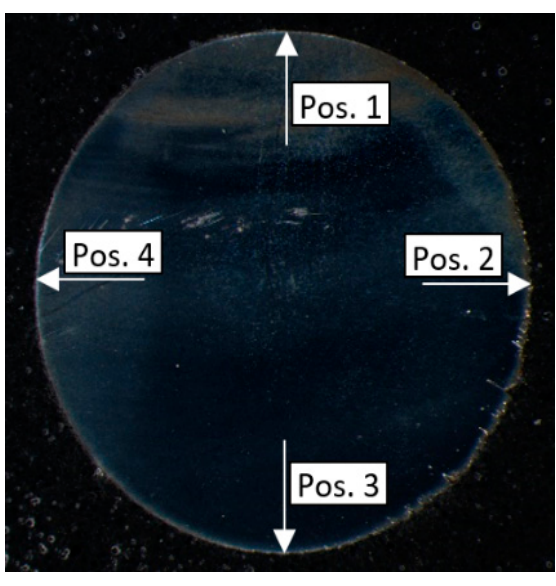

(b)

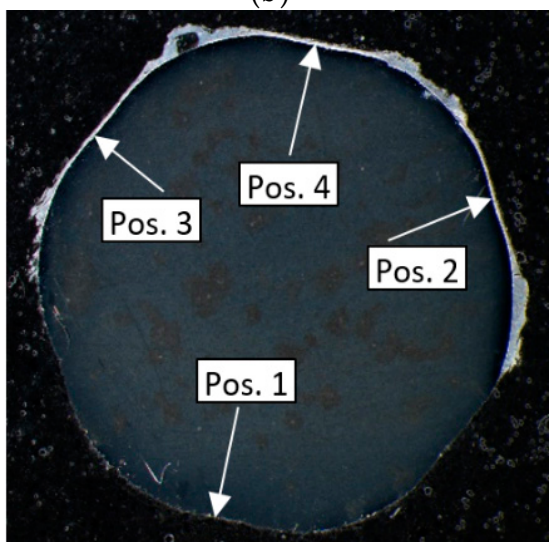

(d)

Figure 3. Macro-views of the cross-sectional area of wires, nominal diameter $5.4 \mathrm{~mm}$ : (a) conventional, (b) phosphated, (c) galvanized, (d) compacted.

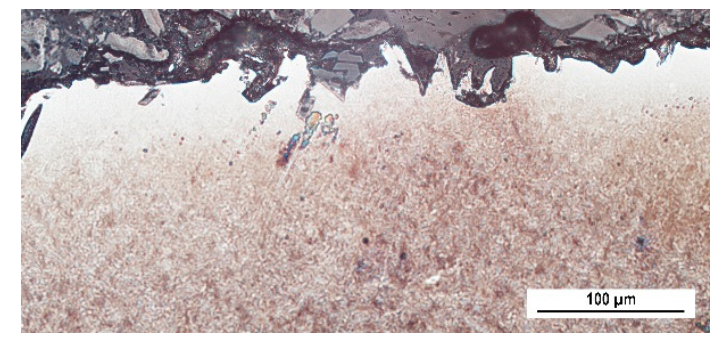

(a)

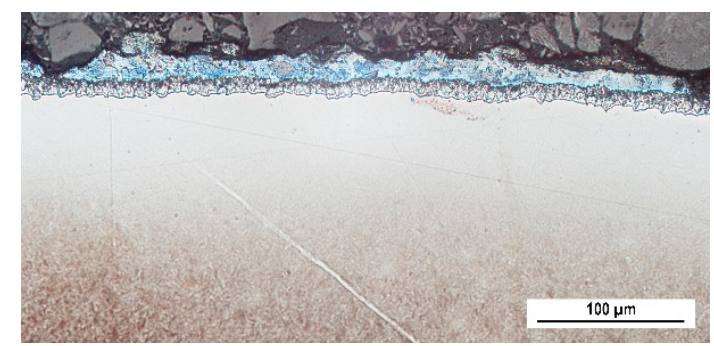

(c)

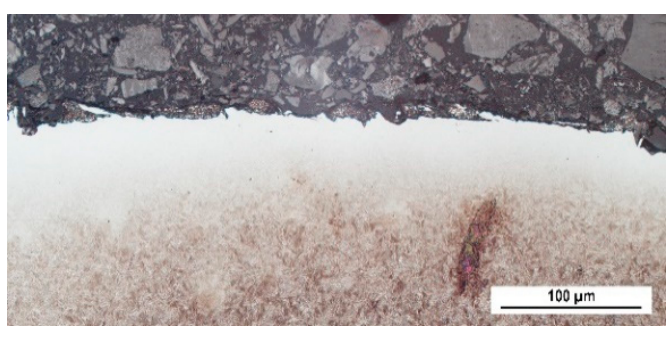

(b)

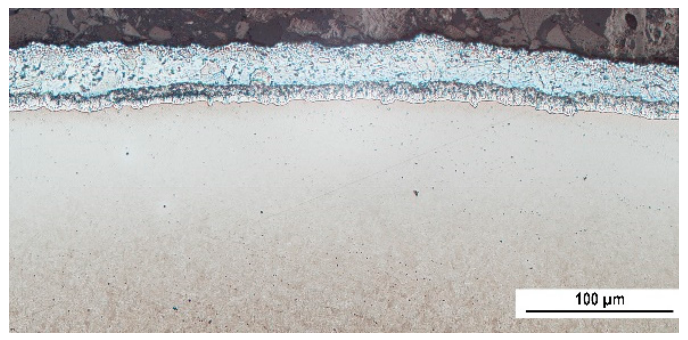

(d)

Figure 4. Metallographic images of galvanized wire surface-cross-sections: (a) position 1, (b) position 2, (c) position 3, (d) position 4. 


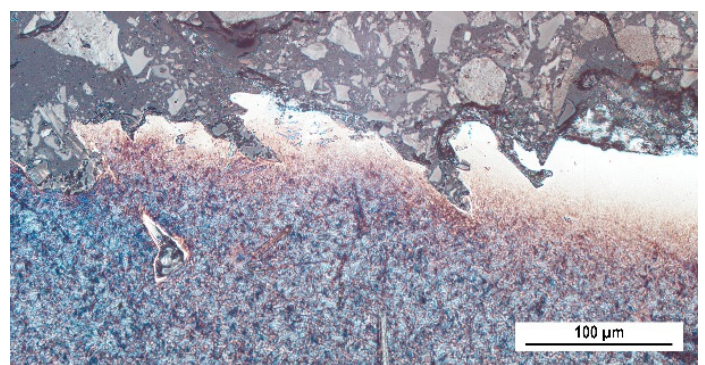

(a)
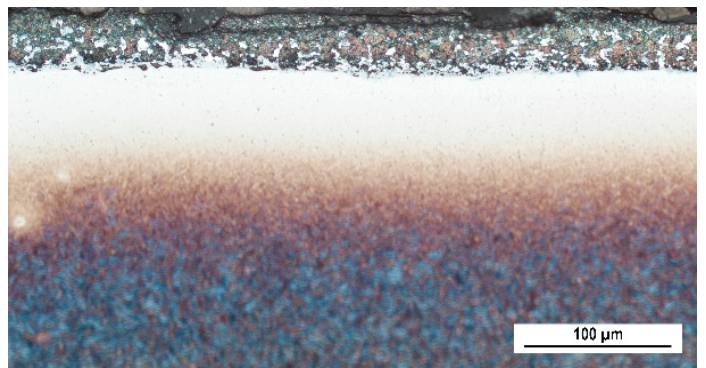

(c)

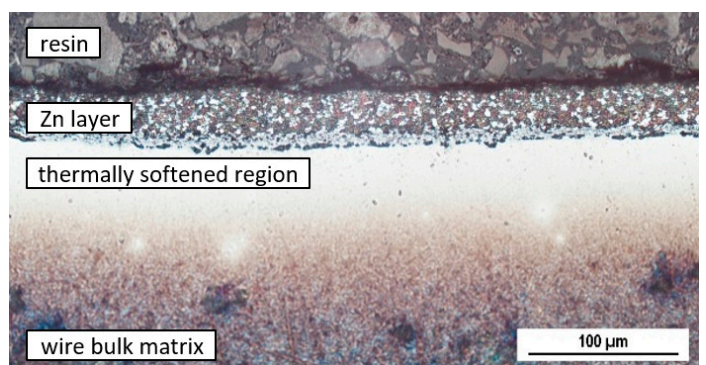

(b)

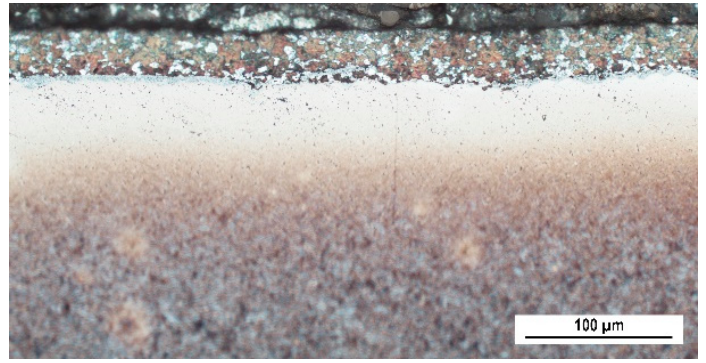

(d)

Figure 5. Metallographic images of compacted wire surface-cross-sections: (a) position 1, (b) position 2, (c) position 3, (d) position 4 .

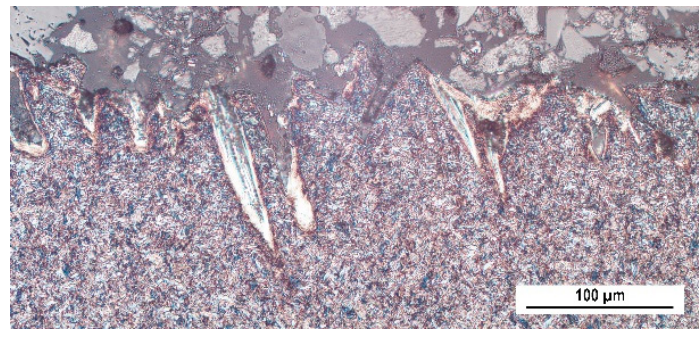

(a)

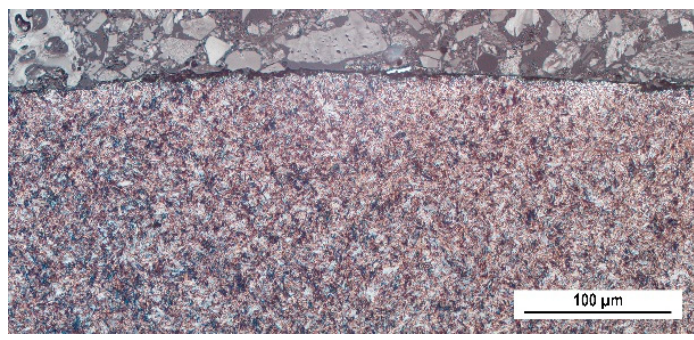

(b)

Figure 6. Metallographic images of phosphated wires surface-cross-sections: (a) position 2, (b) position 4 .

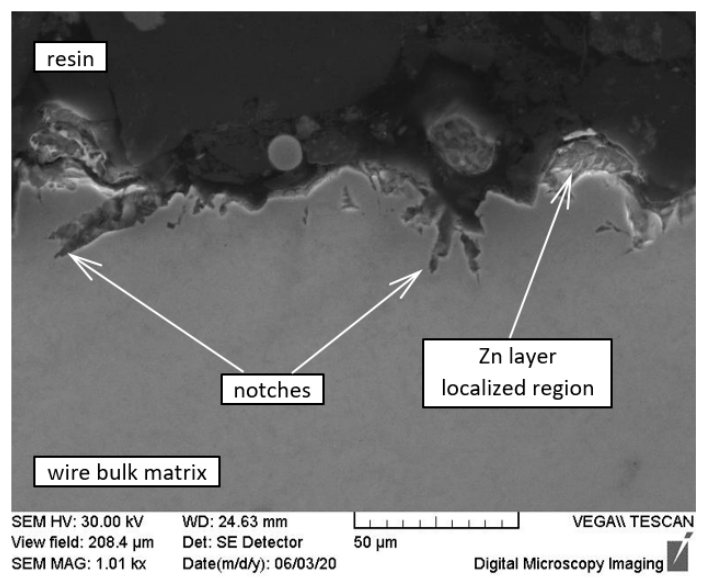

(a)

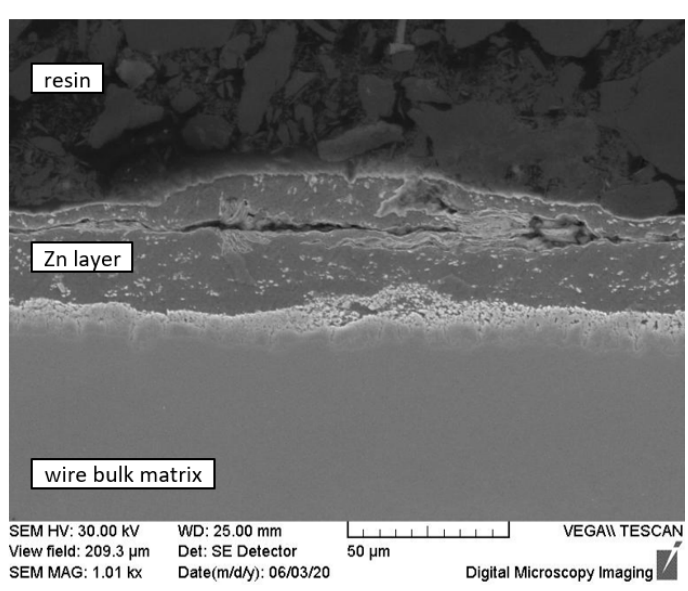

(b)

Figure 7. Cont. 


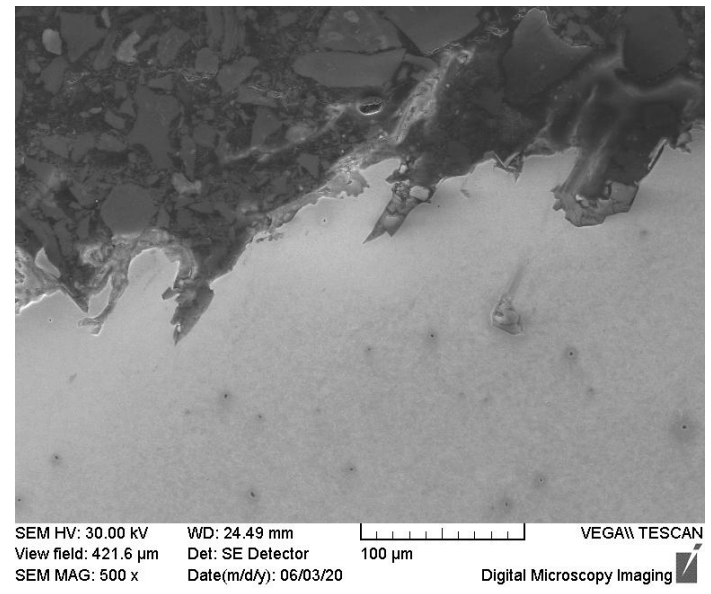

(c)

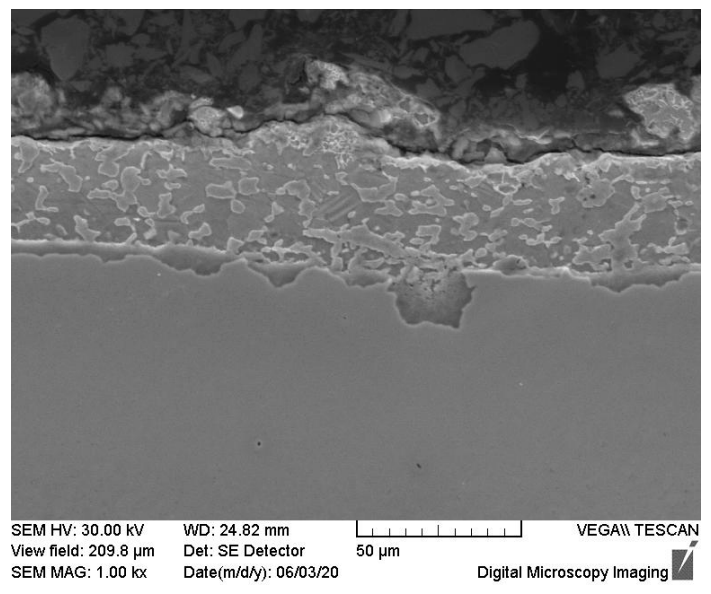

(d)

Figure 7. SEM images of wires: (a) galvanized-position 1, (b) galvanized-position 4, (c) compactedposition 1, (d) compacted-position 4.

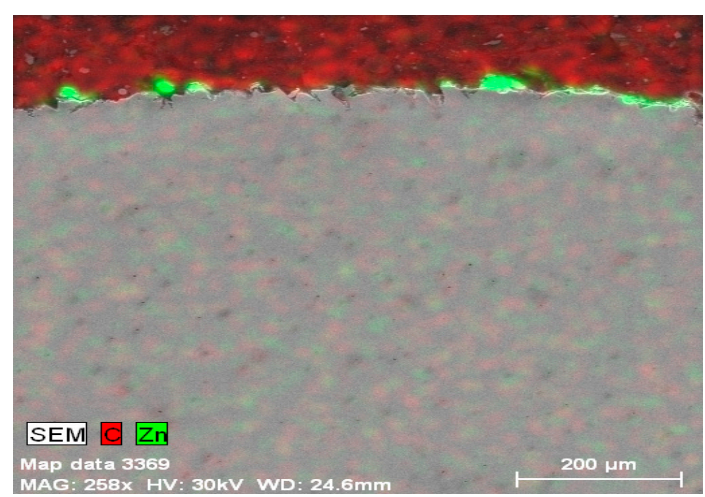

(a)

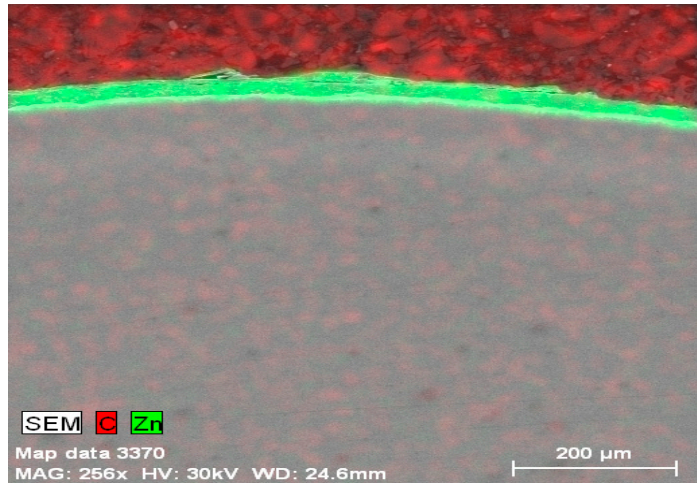

(b)

Figure 8. Chemical maps of galvanized wire: (a) position 1, (b) position 4.

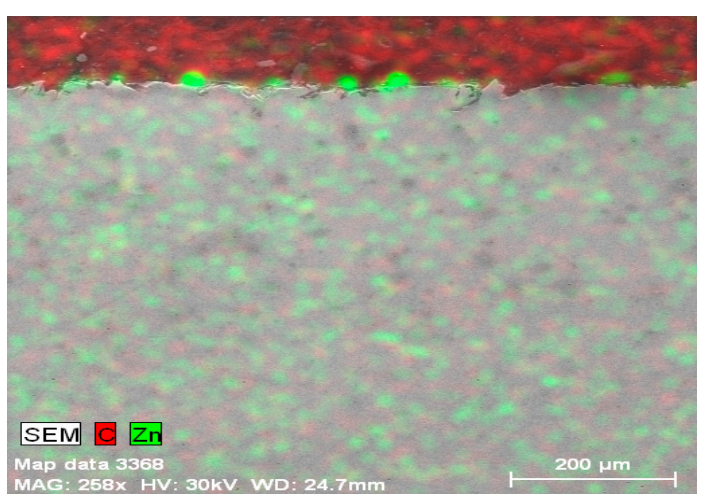

(a)

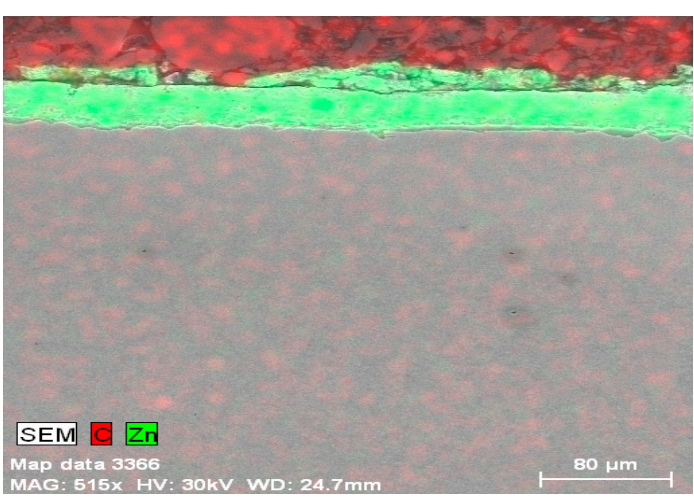

(b)

Figure 9. Chemical maps of compacted wire: (a) position 1, (b) position 4. 


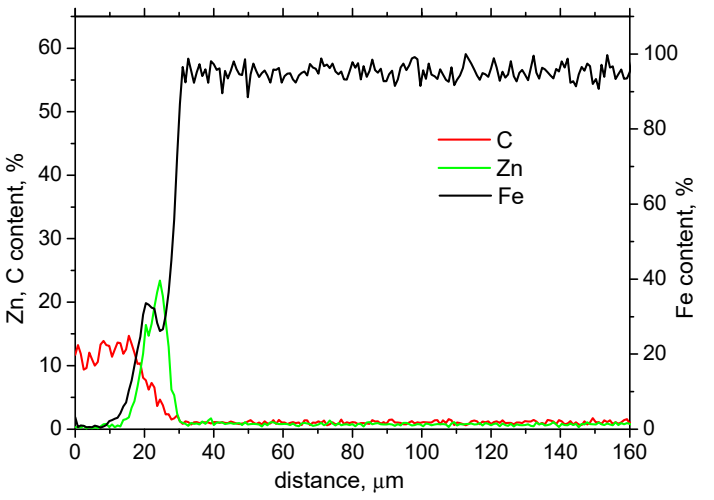

(a)

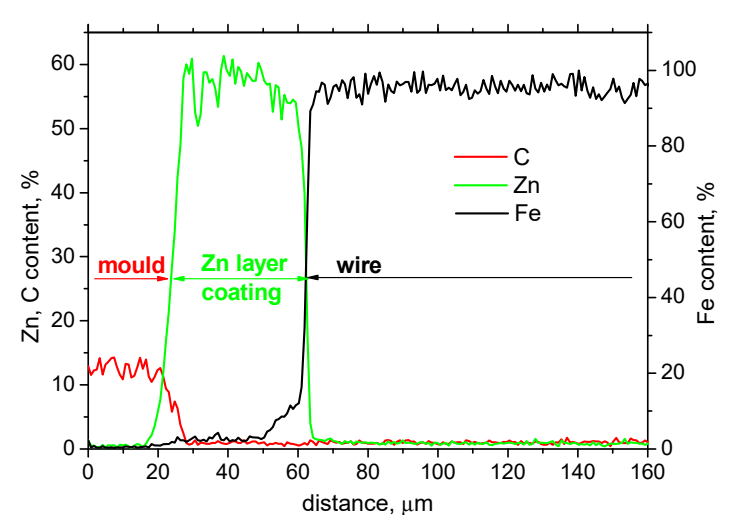

(b)

Figure 10. Linear chemical analysis of galvanized wire: (a) position 1, (b) position 4.

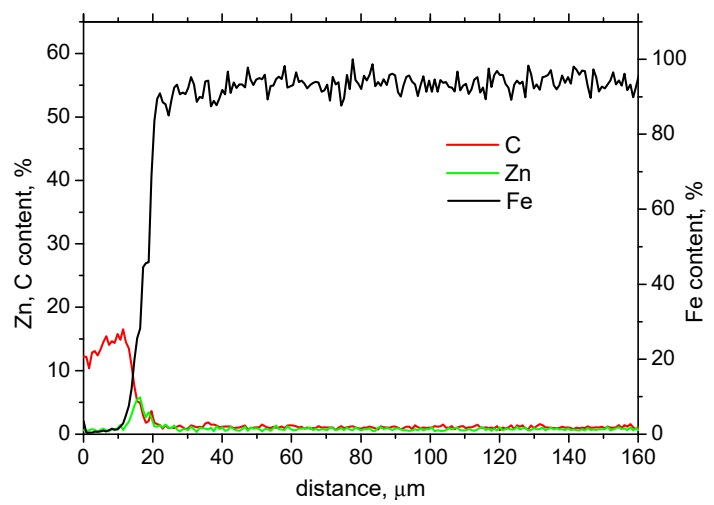

$(\mathbf{a})$

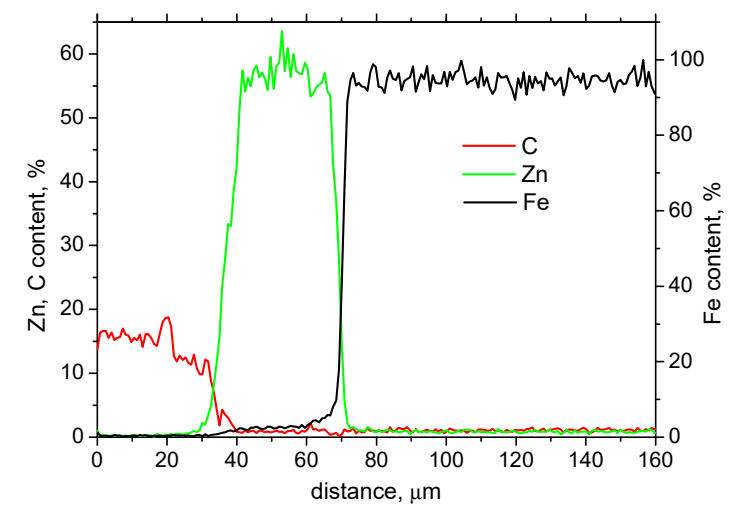

(b)

Figure 11. Linear chemical analysis of compacted wire: (a) position 1, (b) position 4.

\subsection{MBN Measurements}

Tensile stresses usually increase MBN as a result of the preferential alignment of DW in the direction of the exerted load [1]. However, Figure 12 illustrates that MBN decreases progressively (or saturation can be found for the galvanized and compacted wires at higher stresses). Figure 13 demonstrates that the preferential orientation of the wire matrix in the direction of their axis is developed and kept in all wires; the conventional one, as well as the phosphated, galvanized, and compacted. In the case of the galvanized and compacted wires only, the preferential matrix texture is shadowed by decarburizing in the near-surface region (white near-surface region). For this reason, for all wires, DWs were already aligned in the direction of their stress and no additional DW alignment can be initiated by tensile stresses (all magnetocrystalline energy was fully consumed during wire manufacture). 


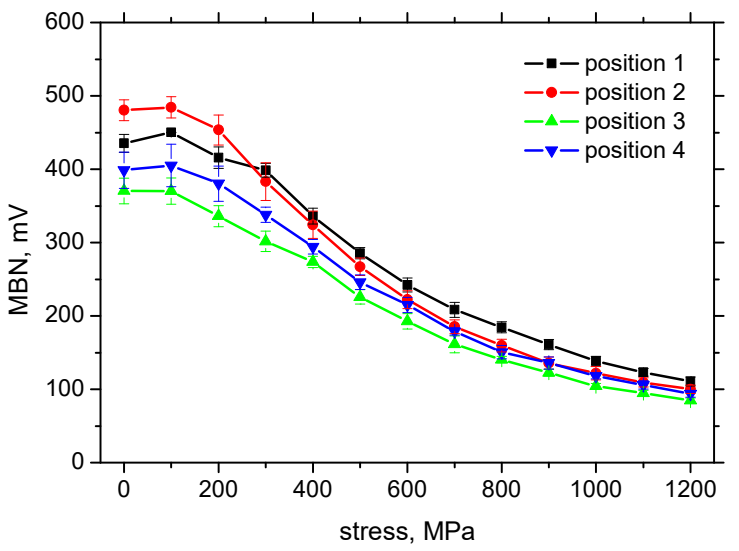

(a)

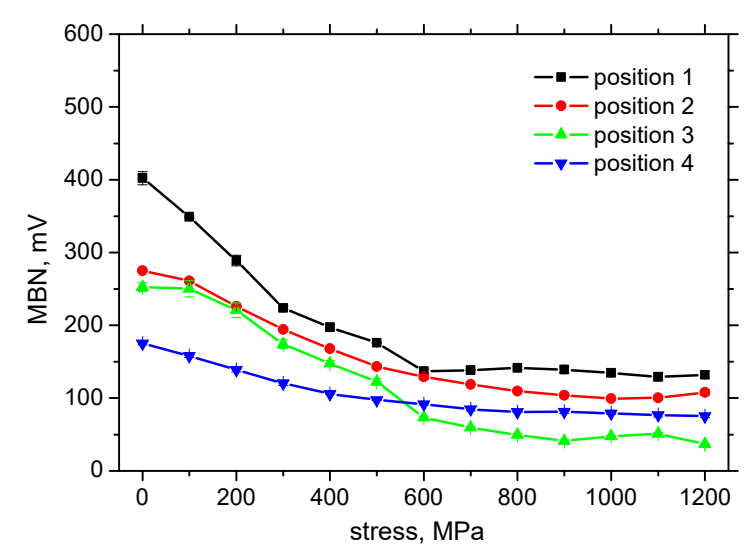

(c)

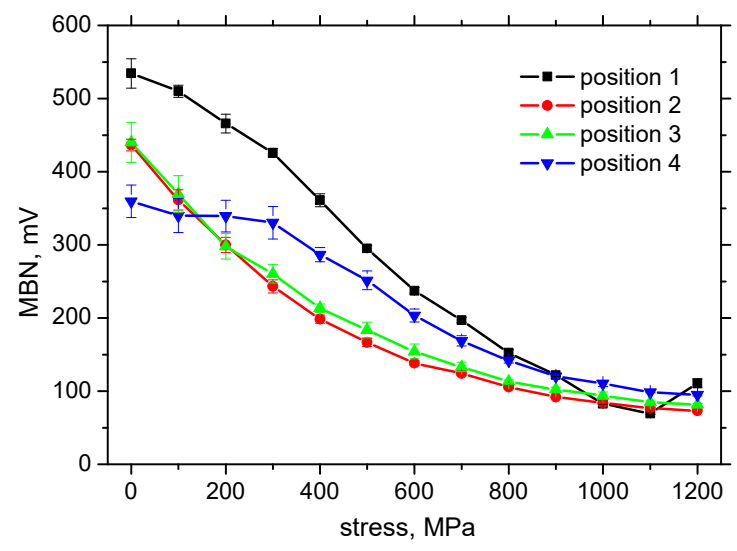

(b)

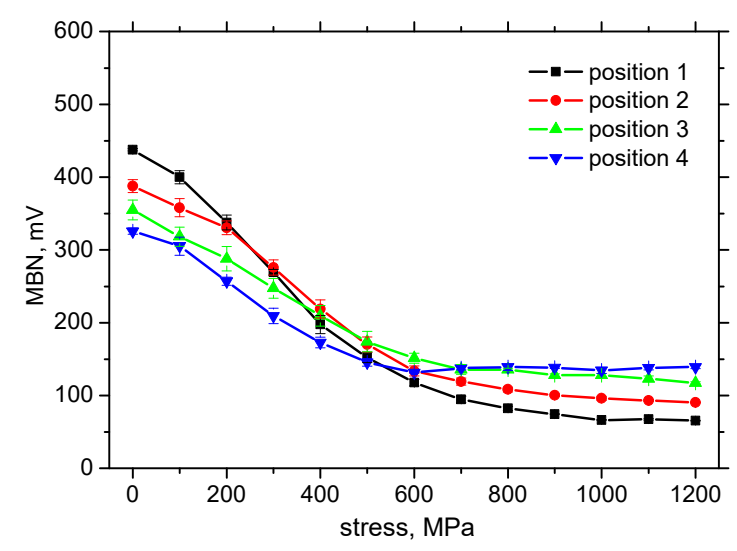

(d)

Figure 12. MBN versus tensile stress: (a) conventional, (b) phosphated, (c) galvanized, (d) compacted.

Figures 12 and 14 also illustrate more pronounced homogeneity in MBN in unloaded conditions with respect to the four different positions on the wire surface for the conventional wire compared with the phosphated one. It is thought that this aspect is driven by the non-homogenous conditions during wire phosphating in the different regions of the wire surface resulting in a non-homogenous micro-hardness distribution (see Table 2). Moreover, the variable surface roughness, when the smooth surface in position 4 is contrasted against the notched one in position 2, also takes a certain role [20]. Increasing height of surface irregularities decrease MBN due to higher demagnetizing fields [20]. However, MBN is lower for positions in which the thick and continuous $\mathrm{Zn}$ layer and smoother wire surface is observed. Therefore, it can be reported that influence of Zn layer (with respect to decreasing MBN) prevails and contribution of uneven surface is minor. Progressively increasing tensile stresses remarkably decreases the difference among the different positions in the case of the conventional and phosphated wires (see Figure 14). It could be expected that the phosphated wire would exhibit higher MBN due to lower surface microhardness as a result of thermal softening during phosphating. However, this aspect is compensated by the presence of $\mathrm{Zn}$ precipitates in the near-surface phosphated layer. These precipitates slow down DWs speed of motion and/or reduce DWs free path of displacement, which in turn reduces the magnitude of MBN pulses and, thus, the entire MBN emission. 


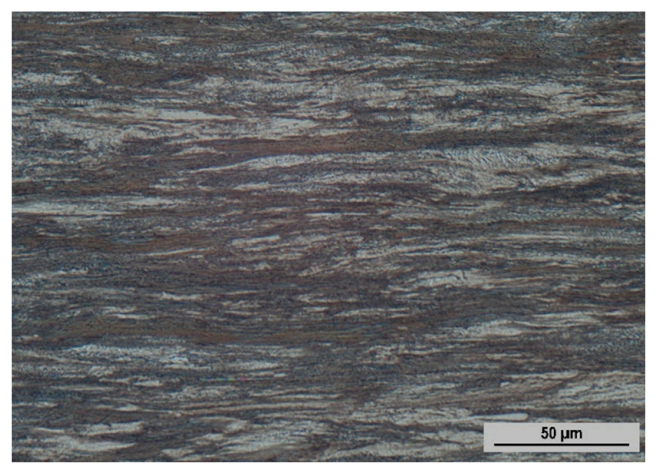

(a)

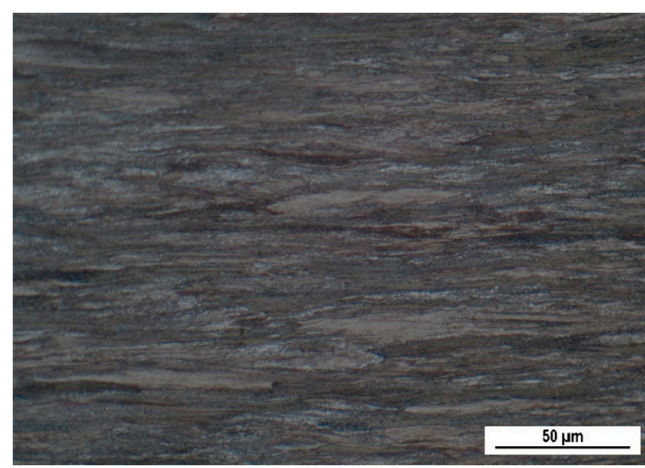

(c)

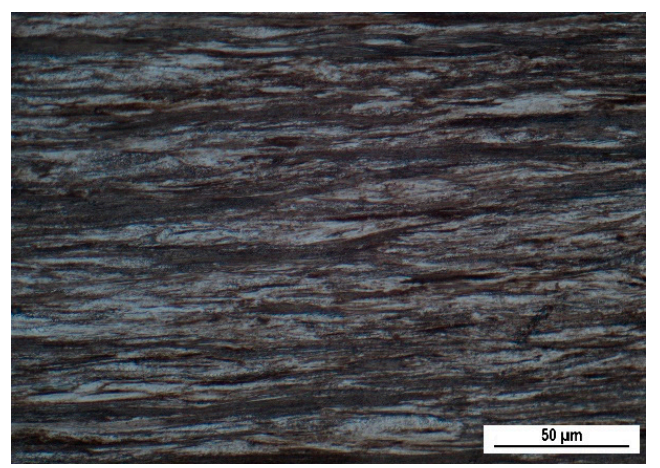

(e)

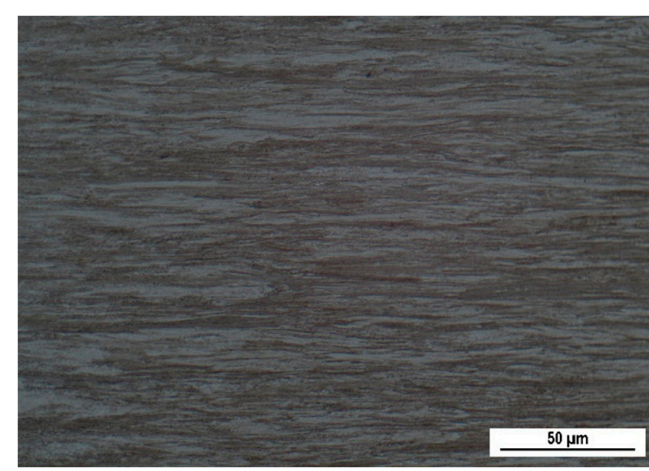

(g)

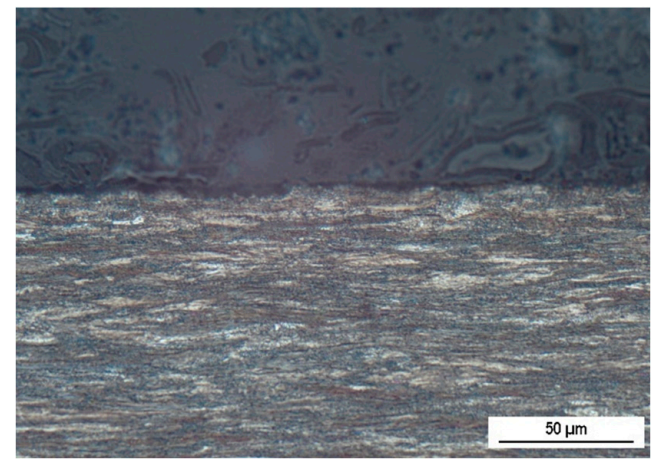

(b)

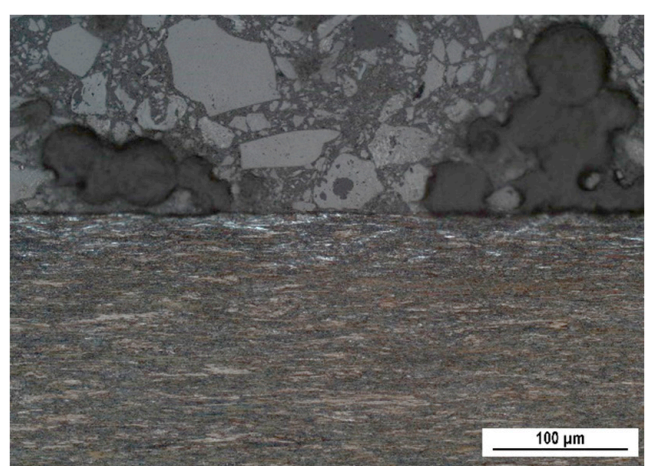

(d)

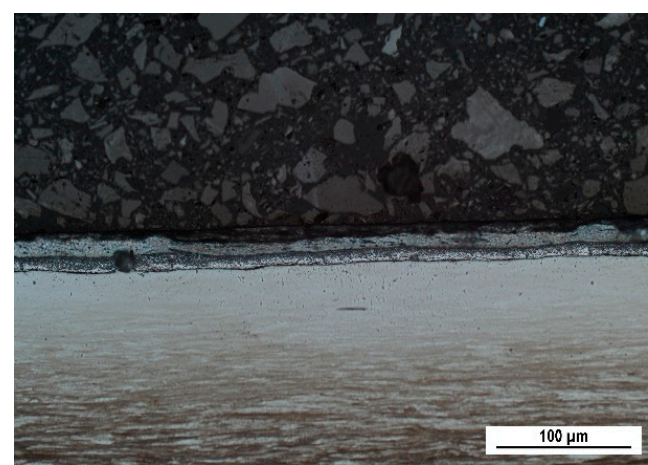

(f)

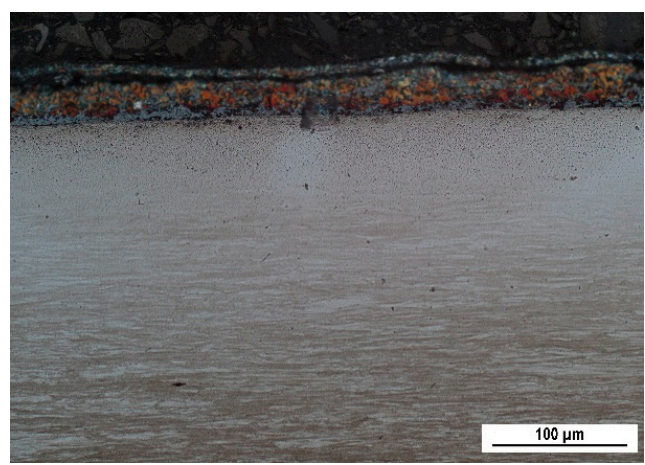

(h)

Figure 13. Metallographic images of wires surface-longitudinal direction: (a) conventional-bulk, (b) conventional—surface, (c) phosphated-bulk, (d) phosphated-surface, (e) galvanized-bulk, (f) galvanized—surface, (g) compacted—bulk, (h) compacted-surface. 


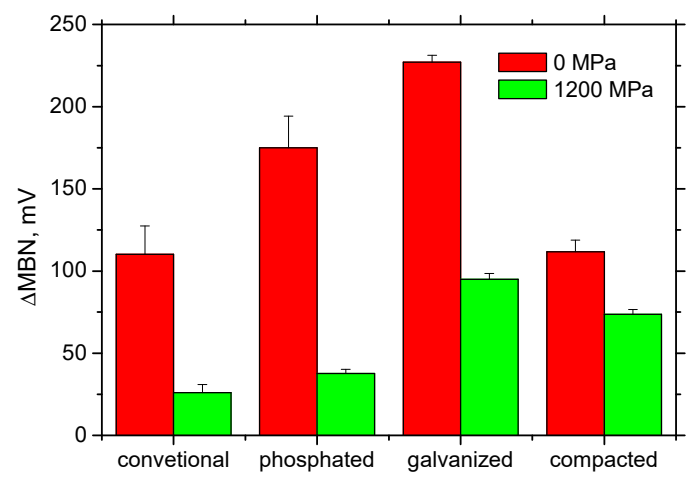

Figure 14. Variation of $M B N-\triangle M B N$ refers to the difference between the maximum and minimum value of MBN found in four different positions.

Table 2. Distribution of microhardness HV0.2 in the wire subsurface region.

\begin{tabular}{ccccc}
\hline Wire & Position 1 & Position 2 & Position 3 & Position 4 \\
\hline Conventional & $497 \pm 8$ & $489 \pm 7$ & $503 \pm 10$ & $495 \pm 10$ \\
Phosphated & $455 \pm 9$ & $468 \pm 8$ & $461 \pm 12$ & $455 \pm 9$ \\
Galvanized & $522 \pm 11$ & $512 \pm 12$ & $505 \pm 8$ & $489 \pm 13$ \\
Compacted & $539 \pm 13$ & $498 \pm 8$ & $514 \pm 4$ & $489 \pm 6$ \\
\hline
\end{tabular}

Wire galvanizing produces a surface non-ferromagnetic layer of variable thickness on the wires. This layer decrease MBN as a result of superimposing the contributions of some aspects. The first one is associated with the increasing gap between the sensor and the wire surface, which makes a weaker magnetic field in the wire. For this reason, some DWs remain unpinned and do not contribute to the MBN emission. A weaker magnitude of magnetizing field also decreases the speed in which magnetizing field $H$ alternates in time $t, d H / d t$, as the force initiating DWs unpinning and affecting their free path of motion [21]. The second aspect is associated with the attenuation of produced MBN pulses during their propagation towards the free surface through the protective layer. The intensity of MBN pulse attenuation grows along with the increasing thickness of the non-ferromagnetic coating on the ferromagnetic matrix [19]. This background explains why the MBN values for galvanized wire are below the MBN for the conventional or phosphated wires (see Figure 12c). Only position 1 exhibits comparable MBN values since this position contains no galvanized layer on the surface (see Figure 4a). MBN for the galvanized wires in the different positions (especially in the unloaded state) is driven by the thickness of the protective layer, as Figure 15a indicates (see also Figure 12c,d and Table 3) since MBN progressively decreases versus layer thickness. Microhardness, in this case, plays no role since the lower microhardness in the positions with a thicker layer should increase MBN but does not (see also Table 2). The concept of galvanized wires results in quite remarkable non-homogeneity of MBN, as Figure 12c demonstrates. This non-homogeneity is driven by the non-homogenous thickness of the galvanized layer on the wire surface (see Figure 14). However, the concept of compacting makes the galvanized layer thickness on the surface more homogenous, which in turn contributes to the lower $\triangle \mathrm{MBN}$ in the unloaded state. More pronounced differences can be found, especially between the uncoated and coated positions only (see Figure 15b). It has been already explained that weaker MBN in the coated positions is driven by the attenuation of MBN pulses propagating toward the free surface through the coating as well as weaker magnetic field in the ferromagnetic matrix which slows down DWs motion. 


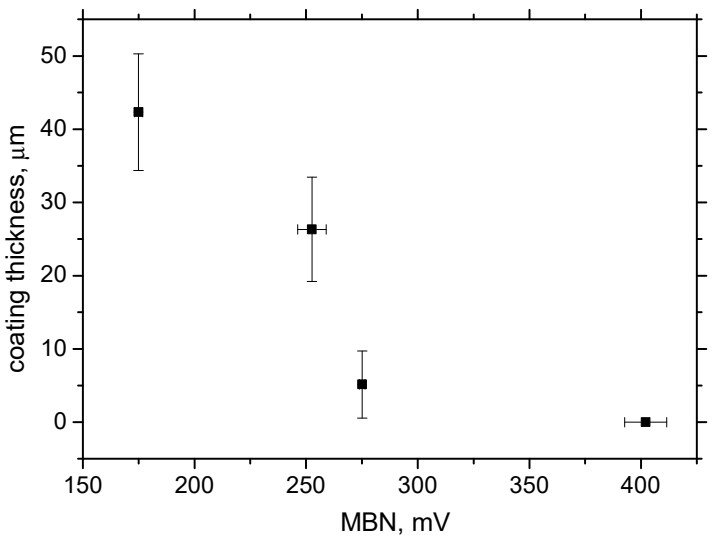

(a)

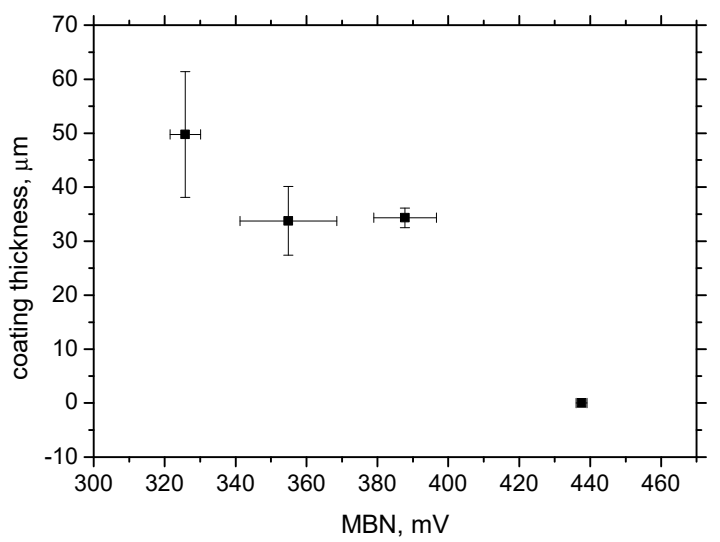

(b)

Figure 15. MBN versus different coating thickness: (a) galvanized, (b) compacted.

Table 3. Thickness of the galvanized layer in micrometers on the surface.

\begin{tabular}{ccccc}
\hline Wire & Position 1 & Position 2 & Position 3 & Position 4 \\
\hline Galvanized & $0 \pm 0$ & $5.8 \pm 3.5$ & $26.3 \pm 7.0$ & $42.3 \pm 7.9$ \\
Compacted & $0 \pm 0$ & $35.3 \pm 1.2$ & $33.7 \pm 6.3$ & $49.7 \pm 11.6$ \\
\hline
\end{tabular}

Finally, MBN for the compacted wires is higher compared with the galvanized wires only despite the higher microhardness of the matrix and thicker galvanized layer (see Figure 12c,d). However, the shape factor plays a role in this case when the sensor magnetizing poles of rounded shape are not in contact with the circular profile wire (as in the case of the galvanized wire, see Figure 3c). A hexagonal final shape is obtained for the compacted wire (see Figure 3d). For this reason, the sensor poles are in contact with the flat surface, which produces more favorable conditions for wire magnetization and MBN pulse acquisition.

Finally, physical background associated with the evolution of MBN versus tensile stress should be discussed. Amiri et al. [22] observed that MBN increased at low tensile stresses, attained a maximum, and then decreased as a result of predominating crystal anisotropy at low stresses, whereas predominating stress anisotropy at higher stresses results in decreasing MBN. Therefore, the easy axis is driven by magnetocrystalline anisotropy at lower stresses when DWs turn in the direction of the magnetic easy axis. However, the new easy axis is controlled by stress at higher tensile stresses [22]. Additionally, Jiles [4] reported that the evolution of MBN is driven by competition between the energy of magnetocrystalline anisotropy and magnetoelastic energy.

The energy of magnetocrystalline anisotropy, $E_{a}$, is a function of magnetocrystalline anisotropy, as Equation (1) indicates for cubic crystals [23].

$$
E_{a}=K_{1}\left(\alpha_{1}^{2} \alpha_{2}^{2}+\alpha_{2}^{2} \alpha_{3}^{2}+\alpha_{1}^{2} \alpha_{3}^{2}\right)+K_{2}\left(\alpha_{1}^{2} \alpha_{2}^{2} \alpha_{3}^{2}\right)
$$

where $\alpha_{1}, \alpha_{2}$, and $\alpha_{3}$ are the direction cosines of the magnetisation vector with respect to three cube edges while $K_{1}$ and $K_{2}$ represent magnetocrystalline anisotropy constants.

The magnetoelastic energy, $E_{\sigma}$, can be expressed as [23]

$$
E_{\sigma}=\left(-3 \lambda_{s} \cos ^{2} \varphi\right) / 2
$$

where $\lambda_{s}$ is the isotropic magnetostriction and $\varphi$ defines the angle between the direction of magnetization and the direction of exerted stress $\sigma$. Increasing MBN with increasing tensile stresses occurs when the magnetocrystalline energy is higher than the magnetoelastic energy. As soon as the magnetoelastic 
energy exceeds the magnetocrystalline energy, a decrease in MBN with increasing tensile stress can be found. Such behavior was also found in a previous study in which the real pre-stress in a steel rope wire was investigated after long-term operation [8].

Figure 12 demonstrates that MBN gradually decreases with increasing tensile stress only since the magnetocrystalline energy $E_{a}$ is fully consumed and MBN evolution is completely driven by the predominating stress anisotropy produced during drawing when sizing wires in dies (remarkable texture). Moreover, the wires are stressed during annealing to prevent future possible relaxation of pre-stress in wires during long-term operation. For this reason, also remarkable, the stress annealing anisotropy contributes to the aforementioned evolution of MBN versus stresses. The stress annealing anisotropy can be expressed as [24]

$$
E_{K u}=-K_{u \sigma} \sin ^{2} \varphi
$$

where $\varphi$ denotes the angle between the direction of magnetization and the stress axis and $K_{u \sigma}$ represents the stress-induced anisotropy constant. As Hilzinger and Rodewald [24] reported, the stress-induced anisotropy $K_{u \sigma}$ increases along with the annealing temperature and is proportional to the applied stress $\sigma$ during annealing. Stress-induced anisotropy is negative (as in this particular case) when the tensional stresses create the easy magnetic axis along the stress axis. This process produces wire of remarkable microstructure and the corresponding magnetic anisotropy when DWs are preferentially oriented in the longitudinal direction (along the wire axis).

\section{Conclusions}

The main role of the MBN technique can be viewed as monitoring true pre-stress. It was demonstrated and explained that low MBN is associated with high pre-stress and vice versa. Figure 12 illustrates the variation of MBN around the wire surface in the unloaded state for the conventional wire and the more pronounced variation for the phosphated one. However, the variation of MBN for both wires decreases with increasing tensile stress. The real pre-stress in the steel rope wires is usually about $1200 \mathrm{MPa}$ and tends to release due to relaxation (when low corrosion extent during long term operation is considered and the corresponding limited over-stressing). Figure 12 also illustrates that the conventional and phosphated wires exhibit good sensitivity of MBN versus tensile stress within the whole range of investigated stresses. On the other hand, this relationship saturates as soon as tensile stress attains $600 \mathrm{MPa}$ in the case of galvanized and compacted wires. For this reason, the concept of the conventional and phosphated wires could be found acceptable when the MBN technique is considered for their pre-stress monitoring. However, the galvanizing increases the variation of $\mathrm{MBN}$ at low tensile stresses and makes it impossible to assess tensile stresses above $600 \mathrm{MPa}$. The non-homogeneity of the surface state and the corresponding variation of MBN values at the different positions increases measurement uncertainty and makes it difficult to assess the true pre-stress in the galvanized wires (since information about the true thickness of the galvanized layer through which MBN measurement is carried is usually missing in real conditions). To increase the reliability of the true pre-stress assessment, more repeat measurements must be carried out.

Author Contributions: Conceptualization, M.M., M.N., and F.B.; Methodology, K.Z. and M.P.; Software, M.N., L.K., and M.M.; Validation, K.Z. and M.P.; Formal analysis, K.Z. and M.P.; Investigation, M.N., F.B., M.U., and L.K.; Resources, F.B and M.P.; Data curation, M.N. and K.Z., Writing—original draft preparation, M.N., L.K., and F.B.; Writing-review and editing, L.K. and K.Z.; Visualization, M.U., L.K., and M.P.; Supervision, K.Z. and F.B.; Project administration, M.M. and M.P.; Funding acquisition, M.M. and M.P. All authors have read and agreed to the published version of the manuscript.

Funding: This study was supported by APVV project No. 14-0772 and VEGA projects Nos. 1/0413/18 and 1/0045/19.

Conflicts of Interest: The authors declare no conflict of interest. 


\section{References}

1. Liu, J.; Tian, G.Y.; Gao, B.; Zeng, K.; Zheng, Y.; Chen, J. Micro-macro characteristics between domain wall motion and magnetic Barkhausen noise under tensile stress. J. Magn. Magn. Mater. 2020, 493, 165719. [CrossRef]

2. Kypris, O.; Nlebedim, I.C.; Jiles, D.C. Measuring stress variation with depth using Barkhausen signals. J. Magn. Magn. Mater. 2016, 407, 377-395. [CrossRef]

3. Karpuschewski, B.; Bleicher, O.; Beutner, M. Surface integrity inspection on gears using Barkhausen noise analysis. Proc. Eng. 2011, 19, 162-171. [CrossRef]

4. Jiles, D. Introduction to Magnetism and Magnetic Materials, 3rd ed.; Taylor \& Francis Group: New York, NY, USA, 2016.

5. Chikazumi, S. Physics of Ferromagnetism, 2nd ed.; Oxford University Press: Oxford, UK, 2005.

6. Sorsa, A.; Santa-Aho, S.; Wartiainen, J.; Souminen, L.; Vippola, M.; Leviskä, K. Effect of shot peening parameters to residual stress profiles and Barkhausen noise. J. Non-Destruct. Eval. 2018, 37, 10. [CrossRef]

7. Gatelier-Rothea, C.; Chicois, J.; Fougeres, R.; Fleischmann, P. Characterization of pure iron and (130 p.p.m.) carbon-iron binary alloy by Barkhausen noise measurements: Study of the influence of stress and microstructure. Acta Metal. 1998, 46, 4873-4882. [CrossRef]

8. Neslušan, M.; Bahleda, F.; Moravčík, M.; Zgútová, K.; Pastorek, F. Assessment of tendons prestressing after long-term service via the Barkhausen noise technique. Materials 2019, 12, 3450. [CrossRef] [PubMed]

9. Neslušan, M.; Bahleda, F.; Minárik, P.; Zgútová, K.; Jambor, M. Non-destructive monitoring of corrosion extent in steel rope wires via Barkhausen noise emission. J. Magn. Magn. Mater. 2019, 484, $179-187$. [CrossRef]

10. Neslušan, M.; Bahleda, F.; Trojan, K.; Pitoňák, M.; Zgútová, K. Barkhausen noise in over-stressed wires. J. Magn. Magn. Mater. 2020, 513, 167134. [CrossRef]

11. Anania, L.; Badala, A.; D'Agata, G. Damage and collapse mode of existing post tensioned precast concrete bridge: The case of Petrulla viaduct. Eng. Struct. 2018, 162, 226-244. [CrossRef]

12. Xu, J.; Sun, H.; Cai, S. Effect of symmetrical broken wires damage on mechanical characteristics of stay cable. J. Sound Vib. 2019, 461, 114920. [CrossRef]

13. Neslušan, M.; Čížek, J.; Kolařík, K.; Minárik, P.; Čilliková, M.; Melikhová, O. Monitoring of grinding burn via Barkhausen noise emission in case-hardened steel in large-bearing production. J. Mater. Process. Technol. 2017, 240, 104-117. [CrossRef]

14. Č́́žek, J.; Neslušan, M.; Čilliková, M.; Mičietová, A.; Melikhova, O. Modification of steel surfaces induced by turning: Non-destructive characterization using Barkhausen noise and positron annihilation. J. Phys. D Appl. Phys. 2014, 47, 445301. [CrossRef]

15. Santa-aho, S.; Vippola, M.; Sorsa, A.; Leiviskä, K.; Lindgren, M.; Lepistö, T. Utilization of Barkhausen noise magnetizing sweeps for case-depth detection from hardened steel. NDTE Int. 2012, 52, 95-102. [CrossRef]

16. Stupakov, A.; Perevertov, O.; Tomáš, I.; Skrbek, B. Evaluation of surface decarburization depth by magnetic Barkhausen noise technique. J. Magn. Magn. Mater. 2011, 323, 1692-1697. [CrossRef]

17. Sorsa, A.; Santa-aho, S.; Aylott, C.; Shaw, B.A.; Vipplola, M.; Leviskä, K. Case depth prediction of nitride samples with Barkhausen noise measurement. Metals 2019, 9, 325. [CrossRef]

18. Čilliková, M.; Uríček, J.; Neslušan, M.; Ballo, V.; Mičietová, A. Monitoring of thermal damage after deposition of coatings via Barkhausen noise technique. Acta Phys. Pol. A 2020, 137, 637-640. [CrossRef]

19. Seemuang, N.; Slatter, T. Using Barkhausen noise to measure coating depth of coated high-speed steel. Int. J. Adv. Manuf. Technol. 2017, 92, 247-258. [CrossRef]

20. Deng, Y.; Li, Z.; Chen, J.; Qi, X. The effect of the structure characteristics on Magnetic Barkhausen noise in commercial steels. J. Magn. Magn. Mater. 2018, 451, 276-282. [CrossRef]

21. Varga, R. Domain Walls and Their Dynamics, 1st ed.; Pavol Jozef Šafárik University: Košice, Slovakia, 2014.

22. Amiri, M.S.; Thielen, M.; Rabung, M.; Marx, M.; Szielasko, K.; Boller, C. On the role of crystal and stress anisotropy in magnetic Barkhausen noise. J. Magn. Magn. Mater. 2014, 372, 16-22. [CrossRef] 
23. Cullity, B.D.; Graham, C.D. Introduction to the Magnetic Materials, 2nd ed.; IEEE Press: Piscataway, NJ, USA, 2009.

24. Hilzinger, R.; Rodewald, W. Magnetic Materials: Fundamentals, Products, Properties, Applications, 1st ed.; Vacuumschmelze GmbH \& Co. KG: Hanau, Germany, 2013.

(C) 2020 by the authors. Licensee MDPI, Basel, Switzerland. This article is an open access article distributed under the terms and conditions of the Creative Commons Attribution (CC BY) license (http://creativecommons.org/licenses/by/4.0/). 